\title{
Lip Changes Following Non-Extraction Orthodontic Treatment
}

ISSN: 2637-7764

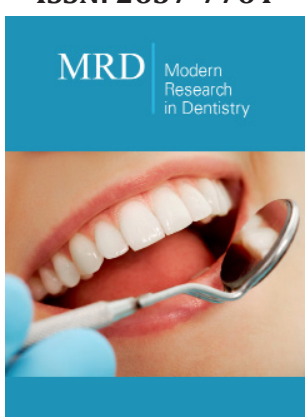

*Corresponding author: Sawsan Tabbaa, Associate Professor, Orthodontics Research Director, School of Orthodontics, Brooks Rehabilitation College of Health Sciences, Jacksonville University, 2800 University Blvd N. Jacksonville. Fl. 32211, USA

Submission: 战 August 01, 2019

Published: 悳 August 08, 2019

Volume 4 - Issue 3

How to cite this article: Kaveh Baharvand Ahmadi, Peter H Buschang, Sawsan Tabbaa. Lip Changes Following NonExtraction Orthodontic Treatment. 4(3) MRD.000587.2019.

DOI: 10.31031/MRD.2019.04.000587

Copyright@ Sawsan Tabbaa, This article is distributed under the terms of the Creative Commons Attribution 4.0 International License, which permits unrestricted use and redistribution provided that the original author and source are credited.

\author{
Kaveh Baharvand Ahmadi ${ }^{1}$, Peter H Buschang ${ }^{2}$ and Sawsan Tabbaa ${ }^{3 *}$ \\ ${ }^{1}$ Orthodontics Private Practice, Texas, USA \\ ${ }^{2}$ Director of Orthodontic Research, Texas A\&M University College of Dentistry, USA \\ ${ }^{3}$ Director of Orthodontic Research, School of Orthodontics, Jacksonville University, USA
}

\begin{abstract}
Introduction: The purpose of this study was to predict the lip changes in Class I adolescents and adults following non-extraction orthodontics treatment.
\end{abstract}

Methods: This longitudinal retrospective study evaluated the pre- and post-treatment lateral cephalograms of 40 adults and 72 adolescents with Angle Class I molar relationships and crowding in both arches. The horizontal and vertical changes of 15 landmarks, along with lip thickness and taper, were evaluated. The sample was randomly divided into two group; $76 \%$ of the subjects were used to develop the multivariate regression formulas; the remaining $24 \%$ served as a validation sample.

Result: Adolescent lips moved inferiorly and anteriorly during treatment; adult lips showed lesser inferior movement, little or no anterior movement and decreases in thickness. Males demonstrated significantly greater inferior and, mostly, greater anterior changes of lip position. The multivariate regressions explained $48-59 \%$ and $41-69 \%$ of the vertical and horizontal variation of the lip changes, respectively. When the prediction equations were applied to the validation sample, with correlations ranged from 0.60-0.84, indicating external validity.

Conclusion: The lip changes of Class I adolescents and adults treated with non-extraction orthodontic treatment can be predicted with fair to moderate accuracy. Adults' lips became compressed and thinner, while the upper lip thickness of adolescents did not change or become slightly thicker.

\section{Introduction}

Esthetic ideals are continuously evolving in today's age of global media and merging cultures. It has been estimated that 3 out of 4 patients come to orthodontists to improve facial attractiveness [1]. Lips are among the most important features that determine attractiveness [2]. For example, lip thickness has been shown to be critical in the perception of beauty, [3,4] with thicker lips being positively related to higher esthetic perceptions [5]. The public notices the lip changes more than nose or chin changes [6]. It is essential for orthodontists to differentiate between lip changes due to treatment and those due to growth. For untreated subjects between 6-18 years of age, upper lip length increases approximately $4 \mathrm{~mm}$, thickness increases $1-2 \mathrm{~mm}$ and protrusion decreases only slightly $(0.5 \mathrm{~mm})$; lower lip length $(9-10 \mathrm{~mm})$ and thickness $(2-3 \mathrm{~mm})$ both increase [7]. Adolescents' lips become relatively more retrusive over time, substantially longer, and somewhat thicker $[8,9]$. In contrast, adults show different patterns of change. Untreated adult soft tissues change at much slower rates. Their lips continue to retrude and tend to flatten, especially at the older ages [10-12].

Relationships between the lips and the underlying dental structures were demonstrated as early as $1834 .{ }^{7}$ Soft tissue changes following the orthodontic treatment are usually considered secondary to tooth and skeletal alterations [13]. Some authors have reported simple linear relationships between hard tissue and soft tissue profile changes $[14,15]$. Ratios, which relate lip changes to the amount of incisor retraction, have been reported to range from 1:1.75 to 1:2.2 for the upper lip, and from 1:1.2 to $1: 1.4$ for the lower lip [16,17]. Importantly, ratios assume that lip movements can be predicted by a single hard tissue measure, which limits their ability to predict $[18,19]$. Moreover, ratios imply that the relationship between hard and soft tissue changes is linear, which is not necessarily the case $[8,20,21]$. Ratios also provide no information about their predictive accuracy. Ratios have been reported to bias soft tissue changes, due to the fact they do not account for the effects of the other independent variables on the measured dependent variable [21]. 
Predicting the changes of the lips during treatment requires information from more than one variable. The changes of the lips measured from the commonly used profile planes are often confounded by growth, so that the actual changes in lip position during treatment can differ not only in magnitude, but also in direction [22]. Treatment changes in both upper and lower lip positions have been explained by a multiple regression formulas using various hard and soft tissue variables, attaining correlations of up to 0.98 [23]. While multiple regressions provide more precise estimates of soft tissue changes than ratios or bivariate regression, and are less biased, it remains controversial whether they produce clinically meaningful predictions for upper lip movements [18]. The purpose of the present study was to predict changes in lip position during non-extraction orthodontic treatment in Class I patients. Previous studies have used mixed (including more than one Angle class) samples, which could be problematic because of the different mechanics utilized could produce a wide range of incisor movements $[13,24,25]$. Moreover, most of the literature focuses on the prediction of the lip response in extraction cases $[8,13,21]$. Lip response to the non-extraction treatment, in which lips can be compressed, might be expected to be different than lip response to extraction treatment, in which the lips are relaxed [26]. There has been only one study that used a multivariate approach to predict the lip changes of a limited sample of non-extraction adult patients [21].

\section{Material and Methods}

\section{Selection criteria}

This longitudinal retrospective study was based on 40 adults and 72 adolescents, with crowding of at least $1 \mathrm{~mm}$ in both the maxilla and mandible who completed a comprehensive orthodontic treatment at Jacksonville University school of Orthodontics. This study was approved by the Research Ethics Committee of the Institutional Review Board (IRB) at Jacksonville University (IRB \# 2016-30). Approximately $64.3 \%$ of subjects were female. The average ages of the adolescents and adults were $13.1 \pm 1.4$ years and $27.4 \pm 1.7$ year, respectively. Females older than 15 years and males older than 17 years were considered to be adults. To be included in the study, the subjects had to have:

A. Angle Class I molar relationships;

B. Radiographs with lips in relaxed position.

C. Non-extraction treatment;

They were excluded if they had:

A. Syndromes, craniofacial anomalies, or congenitally missing teeth;

B. Orthognathic or cosmetic facial surgery.

C. Treatment terminated prematurely due to poor compliance.

D. Poor quality pretreatment (T1) or post-treatment (T2) cephalograms.

\section{Cephalometric procedures and measurements}

All radiographs were taken on calibrated cephalostats, with patients biting on their back teeth. Magnification differences between cephalostats were corrected prior to data analysis using a ruler that was included on each of the cephalograms. Seven soft tissue and 11 hard tissue landmarks were digitized by the primary investigator on each cephalogram (Table 1) (Figure 1) using the Dolphin Imaging Software ${ }^{\oplus}$. The primary investigator superimposed the T1 and T2 tracings using the structural method, as described for the cranial base [27]. The horizontal and vertical changes of the landmarks were evaluated relative to constructed horizontal and vertical reference planes [28-32]. The horizontal reference plane (HRP) was registered on sella (S) and oriented 7 degrees inferior to the sella-nasion (S-N). The vertical reference plane (VRP) is drawn from Sella, perpendicular to the HRP (Figure 1).
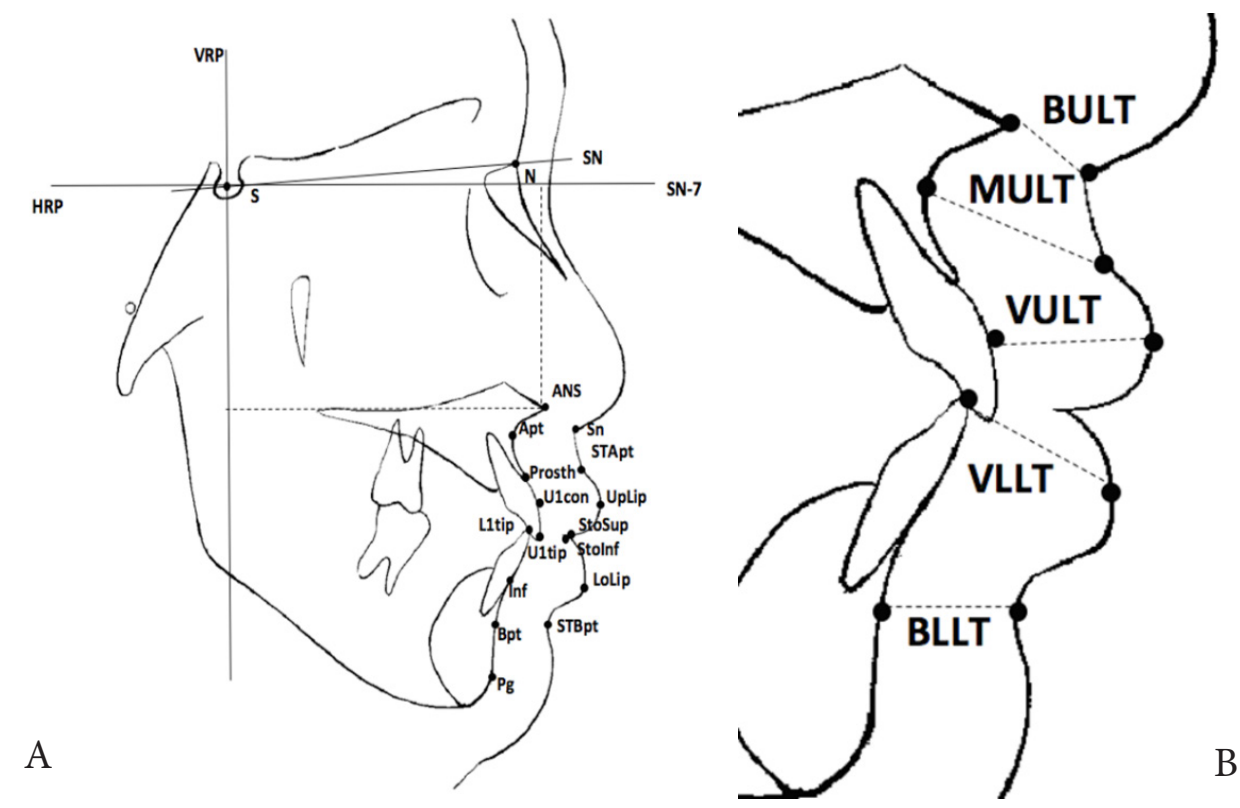

Figure 1: A) Hard and soft tissue landmarks and B) measurement of upper and lower lip thickness. 
Table 1: Hard and soft tissue landmarks.

\begin{tabular}{|c|c|c|}
\hline Hard Tissue Landmarks & Abbreviation & Description \\
\hline Sella & $\mathrm{S}$ & Center of pituitary fossa of sphenoid bone. \\
\hline Nasion & $\mathrm{N}$ & Most anterior point of nasofrontal suture on midsagittal plane \\
\hline Anterior nasal spine & ANS & The anterior tip of the nasal spine \\
\hline A point & Apt & Most posterior point on the concavity of the maxillary alveolar process \\
\hline Prosthion & Prosth & $\begin{array}{c}\text { The most inferior point on the alveolar bone overlying maxillary } \\
\text { incisor }\end{array}$ \\
\hline U1 Convex & U1con & The most convex point on maxillary incisor \\
\hline U1 Tip & U1tip & The most incisal point on the upper incisor \\
\hline L1 Tip & L1tip & The most incisal point on the lower incisor \\
\hline Infradentale & Inf & $\begin{array}{l}\text { The most superior point on the alveolar bone overlying mandibular } \\
\text { incisor }\end{array}$ \\
\hline B point & Bpt & $\begin{array}{l}\text { Most posterior point on the concavity of the mandibular alveolar } \\
\text { process }\end{array}$ \\
\hline Pogonion & $\mathrm{Pg}$ & The most anterior point on the chin \\
\hline \multicolumn{3}{|l|}{ Soft Tissue Landmarks } \\
\hline Subnasale Point & $\mathrm{Sn}$ & $\begin{array}{l}\text { Point at which nasal septum merges with upper cutaneous lip in mid- } \\
\text { sagittal plane }\end{array}$ \\
\hline Soft Tissue A Point & STApt & The most posterior point on the concavity of the upper lip \\
\hline Upper Lip & UpLip & The most anterior point on the margin of the upper lip \\
\hline Stomion Superioris & StoSup & The most inferior point on the margin of the upper lip \\
\hline Lower Lip & LoLip & The most anterior point on the margin of the lower lip \\
\hline Soft Tissue B Point & STBpt & The most posterior point on the concavity of the lower lip \\
\hline Stomion inferioris & StoInf & The most superior point on the margin of the lower lip \\
\hline
\end{tabular}

There were six primary outcome variables (dependent), including soft tissue A point, upper lip point, stomion superioris, lower lip point, soft tissue B point, and stomion inferioris. There were nine independent measures, including the anterior nasal spine, A point, prosthion, U1 convex, U1 tip, L1 tip, infradentale, B point and pogonion. Upper and lower lip thickness and taper

Table 2: Upper and lower lip thickness and taper.

\begin{tabular}{|c|c|c|}
\hline Lip Measurements & Abbreviation & Description \\
\hline Basic Upper Lip Thickness & BULT & The linear distance between ANS and Sn \\
\hline Middle Upper Lip Thickness & MULT distance between Apt and STApt & The linear distance between U1con to UpLip \\
\hline Vermilion Upper Lip Thickness & VULT & VULT-BULT \\
\hline Upper Lip Taper & ULTap linear distance between U1tip to LoLip \\
\hline Vermilion Lower Lip Thickness & VLLT & The linear distance between Bpt to STBpt \\
\hline Basic Lower Lip Thickness & BLLT & VLLT-BLLT \\
\hline Lower Lip Taper & LLTap &
\end{tabular}

\section{Statistical analysis}

SPSS (SPSS Inc, Version 24, Chicago, Ill) was used for the statistical evaluations. Based on skewness and kurtosis, the distributions were all normal. T-tests were used to evaluate between-group differences. Single sample t-tests were used to determine whether positions of the measured landmarks had were also computed (Table 3) (Figure 1). Technical reliability was estimated based on duplicate tracings of 15 randomly selected cephalograms, digitized approximately 14 days apart. Systematic errors were not statistically significant. Method errors ranged from 0.15 to $0.49 \mathrm{~mm}$, with the vertical changes of A point showing the largest random errors. changed significantly during the treatment. Stepwise multiple regression analyses were performed to predict the treatment changes. The sample was randomly divided into two group; $76 \%$ of the subjects were used to develop the regression formulas and the remaining $24 \%$ served as a validation sample. The validation sample was used to ensure that the predictions could be applied to other patients. 
Result

\section{Adolescents vs adults}

Table 3: Comparison of the Vertical changes of the soft and hard tissue changes ( $\mathrm{mm}$ ) in adolescence and adults treated with non-extraction treatment.

\begin{tabular}{|c|c|c|c|c|c|c|c|}
\hline \multicolumn{2}{|c|}{ Variables } & \multicolumn{2}{|c|}{ Adolescence } & \multicolumn{2}{|c|}{ Adults } & \multicolumn{2}{|c|}{ Group Comparison } \\
\hline Landmark & Abbreviation & Mean & SD & Mean & SD & Difference & $\mathbf{P}$ \\
\hline \multicolumn{8}{|c|}{ Maxilla Soft Tissue } \\
\hline ST Subnasale & Sn & -0.82 & 1.74 & 0.12 & 1.02 & -0.93 & 0.001 \\
\hline ST A Point & STApt & -1.36 & 1.83 & -0.11 & 1.28 & -1.25 & $<0.001$ \\
\hline Upper Lip & UpLip & -1.24 & 1.9 & -0.02 & 1.52 & -1.23 & 0.001 \\
\hline Stomion Superioris & StoSup & -1.37 & 1.77 & 0.01 & 1.37 & -1.38 & $<0.001$ \\
\hline Upper Lip Taper & ULTap & 0.04 & 1.92 & -0.28 & 2.16 & 0.32 & 0.788 \\
\hline \multicolumn{8}{|c|}{ Mandible Soft Tissue } \\
\hline ST B Point & STBpt & -1.68 & 2.41 & 0.08 & 2.38 & -1.75 & $<0.001$ \\
\hline Lower Lip & LoLip & -1.45 & 2.56 & 0.31 & 2.41 & -1.75 & 0.001 \\
\hline Stomion Inferioris & StoInf & -0.83 & 2.17 & 0.35 & 2.31 & -1.18 & 0.008 \\
\hline Lower Lip Taper & LLTap & -2.1 & 2.45 & -2.24 & 3.19 & 0.14 & 0.8 \\
\hline \multicolumn{8}{|c|}{ Maxilla Hard Tissue } \\
\hline A Point & Apt & -1.43 & 1.61 & -0.34 & 1.06 & -1.09 & $<0.001$ \\
\hline Prosthion & Prosth & -1.41 & 1.86 & -0.1 & 1.5 & -1.31 & $<0.001$ \\
\hline U1 Most Convex & U1Con & -1.26 & 1.94 & -0.32 & 1.74 & -0.94 & 0.012 \\
\hline U1 tip & U1tip & -1.17 & 1.7 & 0.3 & 1.32 & -1.47 & $<0.001$ \\
\hline \multicolumn{8}{|c|}{ Mandible Hard Tissue } \\
\hline L1 tip & L1tip & -2.89 & 2.11 & -0.92 & 1.78 & -1.97 & $<0.001$ \\
\hline Infradentale & Inf & -1.45 & 2.56 & 0.31 & 2.41 & -2.09 & $<0.001$ \\
\hline B point & Bpt & -2.38 & 2.26 & -0.62 & 1.46 & -1.76 & $<0.001$ \\
\hline Pogonion & $\mathrm{Pg}$ & -2.02 & 2.71 & -1.72 & 2.68 & -0.29 & 0.58 \\
\hline
\end{tabular}

*Statistically significant changes $(\mathrm{P}<0.05)$ are shown in bold.

Table 4: Comparison of the horizontal changes of the soft and hard tissue changes ( $\mathrm{mm}$ ) in adolescence and adults treated with non-extraction treatment

\begin{tabular}{|c|c|c|c|c|c|c|c|c|}
\hline \multicolumn{1}{|c|}{ Variables } & \multicolumn{2}{c|}{ Adolescence } & \multicolumn{3}{c|}{ Adults } & \multicolumn{2}{c|}{ Group Comparison } \\
\hline Landmark & Abbreviation & Mean & SD & Mean & SD & Difference & P \\
\hline \multicolumn{7}{|c|}{ Maxilla Soft Tissue } \\
\hline ST Subnasale & STSubnas & 0.52 & 1.91 & -0.29 & 1.11 & 0.81 & 0.005 \\
\hline ST A Point & STApt & 0.82 & 1.72 & 0.15 & 1.36 & 0.67 & 0.035 \\
\hline Upper Lip & UpLip & 0.53 & 2.04 & -0.2 & 1.25 & 0.73 & 0.02 \\
\hline Stomion Superioris & StoSup & 0.61 & 2.22 & -0.31 & 1.68 & 0.92 & 0.024 \\
\hline Basic Upper Lip Thickness & BULT & -0.09 & 1.73 & -0.38 & 1.29 & 0.29 & 0.332 \\
\hline Middle Upper Lip Thickness & MULT & 0.37 & 1.52 & 0.02 & 1.5 & 0.35 & 0.587 \\
\hline Vermilion Upper Lip Thickness & VULT & -0.04 & 1.66 & -0.67 & 1.88 & 0.62 & 0.231 \\
\hline \multicolumn{2}{|c|}{ Mandible Soft Tissue } & & & \\
\hline ST B Point & STBpt & 1.18 & 2.39 & 0.27 & 1.66 & 0.91 & 0.02 \\
\hline Lower Lip & LoLip & 1.55 & 2.27 & 0.2 & 1.64 & 1.36 & $<0.001$ \\
\hline
\end{tabular}




\begin{tabular}{|c|c|c|c|c|c|c|c|c|c|}
\hline Stomion Inferioris & StoInf & 1.28 & 2.24 & 0.1 & 1.95 & 1.19 & 0.006 \\
\hline Vermilion Lower Lip Thickness & VLLT & -1.19 & 1.94 & -1.34 & 2.61 & 0.15 & 0.721 \\
\hline Basic Lower Lip Thickness & BLLT & 0.96 & 1.36 & 0.76 & 1.75 & 0.2 & 0.338 \\
\hline \multicolumn{7}{|c|}{ Maxilla Hard Tissue } \\
\hline A Point & Apt & 0.5 & 1.43 & -0.01 & 1 & 0.51 & 0.03 \\
\hline Prosthion & Prosth & 0.18 & 1.36 & 0 & 1.14 & 0.18 & 0.485 \\
\hline U1 Most Convex & U1Con & 0.6 & 1.65 & 0.45 & 1.26 & 0.15 & 0.595 \\
\hline U1 tip & U1tip & 1.32 & 2 & 0.98 & 1.95 & 0.34 & 0.379 \\
\hline L1 tip & \multicolumn{2}{|c|}{ Mandible Hard Tissue } & & & \\
\hline L1tip & 1.98 & 2.15 & 0.82 & 1.76 & 1.16 & 0.004 \\
\hline Infradentale & Inf & 1.1 & 2.27 & 0.2 & 1.64 & 0.78 & 0.017 \\
\hline B point & Bpt & 0.29 & 1.64 & -0.25 & 1.41 & 0.54 & 0.083 \\
\hline Pogonion & Pg & 0.85 & 2.12 & 0.48 & 2.68 & 0.37 & 0.425 \\
\hline
\end{tabular}

*Statistically significant changes $(\mathrm{P}<0.05)$ are shown in bold.

Adolescents showed statistically significant $(\mathrm{p}<.05)$ inferior movements of all landmarks (Table 3). Upper lip taper of adolescents did not change and lower lip taper decreased significantly. Four of the adult landmarks showed statistically significant inferior movements (Apt, L1tip, Bpt and Pg). Generally, the hard tissue landmarks showed greater inferior movements than the soft tissue landmarks. With the exception of Pg, LLTap and ULTap, all of the vertical landmarks showed statistically significant differences between adolescents and adults, with adolescents showing greater inferior movements than adults. All of the adolescent landmarks except Bpt and Prosth displayed statistically significant anterior movements (Table 4). Adolescents also showed significant increases in middle upper and lower lip thickness. There were significant increases in adults upper and lower lip thickness, and significant anterior movements of the upper and lower incisors. Ten of the measurements showed statistically significant betweengroup differences. The upper lip and Apt came forward significantly more in adolescents than adults. The lower lip, lower incisor and infradentale came forward significantly more in adolescents.

\section{Male vs female}

Table 5: Comparison of the Vertical changes of the soft and hard tissue changes (mm) in Males and Females treated with non-extraction treatment.

\begin{tabular}{|c|c|c|c|c|c|c|c|}
\hline \multicolumn{2}{|c|}{ Variables } & \multicolumn{2}{|c|}{ Male } & \multicolumn{2}{|c|}{ Female } & \multicolumn{2}{|c|}{ Group Comparison } \\
\hline Landmark & Abbreviation & Mean & SD & Mean & SD & Difference & $\mathbf{P}$ \\
\hline \multicolumn{8}{|c|}{ Maxilla Soft Tissue } \\
\hline ST Subnasale & STSubnas & -1.27 & 1.9 & -0.04 & 1.18 & -1.23 & $<0.001$ \\
\hline ST A Point & STApt & -1.72 & 2.08 & -0.46 & 1.37 & -1.26 & 0.001 \\
\hline Upper Lip & UpLip & -1.85 & 2.02 & -0.23 & 1.49 & -1.63 & $<0.001$ \\
\hline $\begin{array}{c}\text { Stomion } \\
\text { Superioris }\end{array}$ & StoSup & -1.74 & 1.94 & -0.4 & 1.47 & -1.34 & $<0.001$ \\
\hline Upper Lip Taper & ULTap & -0.11 & 2.09 & 0.01 & 1.83 & -0.11 & 0.788 \\
\hline \multicolumn{8}{|c|}{ Mandible Soft Tissue } \\
\hline ST B Point & STBpt & -2.24 & 2.25 & -0.39 & 2.45 & -1.86 & $<0.001$ \\
\hline Lower Lip & LoLip & -2.09 & 2.35 & -0.12 & 2.53 & -1.97 & $<0.001$ \\
\hline $\begin{array}{l}\text { Stomion } \\
\text { Inferioris }\end{array}$ & StoInf & -1.4 & 1.79 & 0.14 & 2.35 & -1.54 & $<0.001$ \\
\hline Lower Lip Taper & LLTap & -2.1 & 2.45 & -2.24 & 3.19 & 0.14 & 0.8 \\
\hline \multicolumn{8}{|c|}{ Maxilla Hard Tissue } \\
\hline A Point & Apt & -1.74 & 1.9 & -0.65 & 1.12 & -1.08 & 0.002 \\
\hline Prosthion & Prosth & -1.92 & 1.84 & -0.4 & 1.63 & -1.52 & $<0.001$ \\
\hline U1 Most Convex & U1Con & -1.86 & 1.93 & -0.4 & 1.71 & -1.47 & $<0.001$ \\
\hline U1 tip & U1tip & -1.57 & 1.76 & -0.13 & 1.47 & -1.44 & $<0.001$ \\
\hline
\end{tabular}




\begin{tabular}{|c|c|c|c|c|c|c|c|}
\hline \multicolumn{9}{|c|}{ Mandible Hard Tissue } \\
\hline L1 tip & L1tip & -3.45 & 2.12 & -1.49 & 1.93 & -1.96 & $<0.001$ \\
\hline Infradentale & Inf & -2.92 & 1.99 & -1.09 & 1.9 & -1.83 & $<0.001$ \\
\hline B point & Bpt & -2.92 & 2.08 & -1.11 & 1.96 & -1.81 & $<0.001$ \\
\hline Pogonion & Pg & -1.96 & 2.63 & -1.89 & 2.73 & -0.07 & 0.889 \\
\hline
\end{tabular}

*Statistically significant changes $(\mathrm{P}<0.05)$ are shown in bold.

Table 6: Comparison of the horizontal changes of the soft and hard tissue changes ( $\mathrm{mm}$ ) in Males and Females treated with non-extraction treatment.

\begin{tabular}{|c|c|c|c|c|c|c|c|}
\hline \multicolumn{2}{|c|}{ Variables } & \multicolumn{2}{|c|}{ Male } & \multicolumn{2}{|c|}{ Female } & \multicolumn{2}{|c|}{ Group Comparison } \\
\hline Landmark & Abbreviation & Mean & SD & Mean & SD & Difference & $\mathbf{P}$ \\
\hline \multicolumn{8}{|c|}{ Maxilla Soft Tissue } \\
\hline ST Subnasale & STSubnas & 0.56 & 1.88 & 0.05 & 1.6 & 0.52 & 0.127 \\
\hline ST A Point & STApt & 0.96 & 1.97 & 0.37 & 1.36 & 0.59 & 0.099 \\
\hline Upper Lip & UpLip & 0.59 & 2.25 & 0.09 & 1.53 & 0.49 & 0.221 \\
\hline $\begin{array}{l}\text { Stomion Supe- } \\
\text { rioris }\end{array}$ & StoSup & 0.48 & 2.4 & 0.17 & 1.89 & 0.32 & 0.444 \\
\hline $\begin{array}{l}\text { Basic Upper Lip } \\
\text { Thickness }\end{array}$ & BULT & 0.11 & 1.85 & -0.37 & 1.44 & 0.48 & 0.332 \\
\hline $\begin{array}{l}\text { Middle Upper } \\
\text { Lip Thickness }\end{array}$ & MULT & 0.51 & 1.64 & 0.1 & 1.44 & 0.41 & 0.587 \\
\hline $\begin{array}{l}\text { Vermilion Upper } \\
\text { Lip Thickness }\end{array}$ & VULT & -0.16 & 2.22 & -0.32 & 1.47 & 0.16 & 0.231 \\
\hline \multicolumn{8}{|c|}{ Mandible Soft Tissue } \\
\hline ST B Point & STBpt & 0.68 & 2.62 & 0.95 & 1.93 & -0.27 & 0.572 \\
\hline Lower Lip & LoLip & 1.25 & 2.72 & 0.97 & 1.79 & 0.27 & 0.569 \\
\hline $\begin{array}{l}\text { Stomion Infe- } \\
\text { rioris }\end{array}$ & StoInf & 0.93 & 2.32 & 0.82 & 2.16 & 0.11 & 0.808 \\
\hline $\begin{array}{l}\text { Vermilion Lower } \\
\text { Lip Thickness }\end{array}$ & VLLT & -1.3 & 1.86 & -1.14 & 2.61 & -0.16 & 0.721 \\
\hline $\begin{array}{c}\text { Basic Lower Lip } \\
\text { Thickness }\end{array}$ & BLLT & 0.8 & 1.36 & 1.1 & 1.75 & -0.3 & 0.338 \\
\hline \multicolumn{8}{|c|}{ Maxilla Hard Tissue } \\
\hline A Point & Apt & 0.47 & 1.33 & 0.23 & 1.31 & 0.25 & 0.344 \\
\hline Prosthion & Prosth & 0.25 & 1.48 & 0.04 & 1.16 & 0.21 & 0.447 \\
\hline U1 Most Convex & U1Con & 0.68 & 1.61 & 0.47 & 1.47 & 0.21 & 0.494 \\
\hline U1 tip & U1tip & 1.42 & 2.24 & 1.08 & 1.82 & 0.34 & 0.381 \\
\hline \multicolumn{8}{|c|}{ Mandible Hard Tissue } \\
\hline L1 tip & L1tip & 1.74 & 2.25 & 1.48 & 2 & 0.26 & 0.53 \\
\hline Infradentale & Inf & 0.96 & 1.91 & 0.74 & 1.54 & 0.22 & 0.506 \\
\hline B point & Bpt & -0.06 & 1.86 & 0.18 & 1.41 & -0.24 & 0.443 \\
\hline Pogonion & $\mathrm{Pg}$ & 0.86 & 2.65 & 0.63 & 2.2 & 0.23 & 0.624 \\
\hline
\end{tabular}

*Statistically significant changes $(\mathrm{P}<0.05)$ are shown in bold. 
Males showed statistically significant vertical changes of all measurements (Table 5); 10 measures (mostly hard tissues) changed significantly in females. L1tip and STBpt showed the greatest inferior movements among the hard and soft tissues measures, respectively. With the exception of lip taper and Pg, all the vertical measures showed significant sex differences. Males underwent significantly more inferior movement than females.
There were no significant sex differences for changes of lip taper. Except for 4 of the landmarks (UpLip, StoSup, Prosth and Bpt) males demonstrated significant anterior movements (Table 6). Females showed significant anterior movements of all landmarks except STSubnas, UpLip, Sto, SupProsth, and Bpt. Basic lower lip thick increased and vermilion thickness decreased. There were no sex differences in the horizontal changes that occurred.

\section{Multivariate stepwise regression analyses and validation}

Table 7: Stepwise multiple regression models for the upper and lower lip changes for hard and soft tissue variables.

\begin{tabular}{|c|c|c|c|c|c|c|c|c|c|c|}
\hline \multirow{2}{*}{$\begin{array}{c}\text { Depen- } \\
\text { dent } \\
\text { Variable }\end{array}$} & \multirow{2}{*}{$\mathbf{R}$} & \multirow{2}{*}{$\begin{array}{c}\text { SE of Es- } \\
\text { timate }\end{array}$} & \multirow{2}{*}{$\begin{array}{l}\text { Con- } \\
\text { stant }\end{array}$} & \multicolumn{6}{|c|}{ Prediction Equation } & \multirow{2}{*}{$\begin{array}{c}\text { Vali- } \\
\text { dation } \\
\text { Sam- } \\
\text { ple(R) }\end{array}$} \\
\hline & & & & 1st & 2nd & 3rd & 4th & 5th & 6th & \\
\hline \multicolumn{11}{|c|}{ Vertical Changes } \\
\hline STApt & 0.76 & 1.16 & -1.2 & 0.36(Prosth-y) & 0.34 (ANS-y) & 0.29 (Apt-y) & 0.07(IULMT) & & & 0.9 \\
\hline UpLip & 0.76 & 1.22 & -0.2 & 0.59(U1tip-y) & 0.38(Apt-y) & 0.12 (L1tip-x) & & & & 0.68 \\
\hline StoSup & 0.77 & 1.13 & -0.13 & 0.37(U1tip-y) & 0.28 (Apt-y) & 0.24 (Prosth-y) & $0.15(B p t-x)$ & & & 0.76 \\
\hline StoInf & 0.69 & 1.68 & -1.98 & 0.57(L1tip-y) & 0.40 (ILLT) & 1.02 (Sex) & & & & 0.81 \\
\hline LoLip & 0.77 & 1.72 & -5.81 & 0.60 (Inf-y) & 0.27 (ILLT) & 1.37 (Sex) & 0.34 (Apt-y) & 0.25 (ILLVT) & & 0.86 \\
\hline STBpt & 0.72 & 1.78 & -0.29 & 0.64(L1tip-y) & 0.40(U1tip-y) & 0.16 (ILLT) & & & & 0.82 \\
\hline \multicolumn{11}{|c|}{ Horizontal Changes } \\
\hline STApt & 0.77 & 1.08 & 1.24 & 0.60 (Prosth-x) & 0.21 (Inf-x) & $-0.23($ Apt-Y) & 0.19 (ANS-x) & -0.08 (IULMT) & 0.58 (Race) & 0.68 \\
\hline UpLip & 0.74 & 1.26 & 3.86 & 0.66(Prosth-x) & 0.27 (Inf-x) & -0.17 (IULBT) & -0.22 (ANS-y) & $-0.74(\operatorname{Sex})$ & $\begin{array}{c}-0.07(\text { IUL- } \\
\text { MT) }\end{array}$ & 0.65 \\
\hline StoSup & 0.64 & 1.63 & -0.3 & 0.65(Prosth-x) & $0.36($ Inf-x) & -0.28(ANS-y) & & & & 0.60 \\
\hline StoInf & 0.74 & 1.5 & 2.94 & 0.59 (Inf-x) & 0.38(U1tip-x) & -0.26 (ILLBT) & $-0.19(P g-x)$ & & & 0.74 \\
\hline Lolip & 0.79 & 1.36 & 2.57 & 0.93(Inf-x) & -0.22 (ILLBT) & -0.16 (Prosth-y) & & & & 0.78 \\
\hline STBpt & 0.83 & 1.24 & -0.94 & $0.63($ Inf-x) & $0.36($ Bpt-x $)$ & 0.15 (ILLT) & 0.23 (ANS-x) & 0.55 (Sex) & & 0.84 \\
\hline
\end{tabular}

The multivariate stepwise regressions produced correlations explained $48-59 \%$ of the variations. The vertical changes of prosthion and ANS were the most important variables predicting the vertical changes of STApt, whereas the U1tip and Apt were the most important for predicting UpLip and StoSup (Table 7). The vertical changes of the lower lip were most closely associated with L1tip, ILLT and sex. When the regression equations were applied to the validation sample, the associations (ranging from 0.680.90 ) between the actual and predicted changes were generally stronger than the original correlations. The regressions (Table 7) explained $41-69 \%$ of the variation in the horizontal changes of the lips that occurred during treatment. Three to six variables entered the predictive equations. The horizontal changes of prosthion and infradentale were the two measures most closely associated with horizontal upper lip changes, while the horizontal changes of infradentale was most closely related to horizontal lower lip changes. Similar relations were produced when the prediction equations were applied to the validation sample, with correlations ranging from $0.60-0.84$.

\section{Discussion}

Incisors procline in the adult non-extraction cases treated for crowding. The present study showed forward movements of the upper and the lower incisor crowns. Forward tipping of the incisors in non-extraction treatment has been reported [33,34]. Proclination of the incisors in adults could have been the result of leveling and alignment. In addition, slightly more proclination of the upper than lower incisors was observed in the present than previous studies, possibly due to the MBT prescription (+17 degrees of torque for upper incisors, -6 degrees for lower incisors) that was used to treat the patients. Adult lip thickness decreases as a result of nonextraction treatments. Based on the present study, the lips did not move forward significantly, despite the forward movement of the underlying hard tissue. This shows that non-extraction treatment in adults compresses the lips slightly, decreasing upper and the lower vermilion thickness. Both decreases [34] and increases [35] of upper lip thickness have been reported after non-extraction treatment of white subjects. The increases were observed for a 
mixed sample of adults and adolescents, which could have been affected by growth.

Little or no growth was expected for the adults in the present study, and the changes can be attributed mainly to treatment. Unlike adults, adolescents undergo inferior growth movements of both the soft and hard tissues. The soft tissue changes followed the same direction as the underlying hard tissues: the lips became longer as the underlying hard tissue grew inferiorly. Inferior movements of adolescent lips have been reported in multiple growth studies [3638]. Based on the differences in the vertical soft tissue changes of adults and adolescents, growth must be considered as the major factor determining the inferior movements observed. During nonextraction treatment, most hard and soft tissue landmarks (except prosthion and B point) moved anteriorly in adolescents. Contrary to adults, who showed thinning of lips with treatment, the upper lip of adolescents did not change or became slightly thicker. Increases in lip thickness are expected in the untreated adolescents, especially in the mid-lip region $[4,6]$. Increases of the upper lip thickness and decreases of the lower lip vermilion thickness have been previously reported for adolescents treated nonextraction [39]. It appears that the normal thickening of the upper lip and the vermilion part of the lower lip that occurs in untreated adolescents is camouflaged by treatment.

The basic part of the lower lip exhibits both growth and treatment thickening effects. Males experienced more inferior movement of the hard and soft tissues than females. In the present study, the upper and the lower lips followed the underlying hard tissues, and moved more inferiorly in males than females. While upper lip length increased similarly in both sexes, lower lip increased only in males. Increases of the upper lip length in untreated males and females have been reported after 11 years of age [38]. Since the present sample consisted of both growing and non-growing patients, growth probably interacted with treatment to produce the lip response observed. There are no sex differences in the horizontal changes in lip position during non-extraction treatment. The present study showed no differences in the horizontal movements of the soft tissue landmarks, nor in the changes of the lip thickness that occurred. Subtelny [40] reported sex differences in untreated subjects, with males showing greater increases in lip thickness than females, especially at the vermilion borders $[38,40]$. Oliver reported greater increases in the upper lip thickness in the orthodontically treated growing males than females [41]. However, it was not clear if Oliver's sample was treated with extractions or non-extraction. In the present study, the lips were growing and the incisors proclined. As previously explained, lips are compressed as the hard tissues are moved anteriorly, counteracting the effects of growth. While the stepwise multiple regressions in the present study provided more precise estimates than simple bivariate regression, the predictions were only fair to moderate. Previous studies also have reported better predictability using a regression model, as might be expected $[18,20,23,25,34]$.

The regression models required at least three independent variables to explain the variability of the lip changes, substantiating the complexity of soft tissues changes that occur during treatment. The regression models in the present study explained $48-59 \%$ of the variability of the vertical changes of the lips. Changes in the positions of prosthion and the upper incisor tip were most closely related to the vertical changes of the upper lip. Similarly, infradentale and the tip of the lower incisor were most closely related to changes of lower lip position. Prosthion has previously been identified as an important hard tissue landmark related to the upper lip changes, $[2,8,23]$ as has the tip of the upper incisor, $[8,20]$ infradentale [8] and tip of the lower incisors [21,25]. While no other study has used multiple regression to predict vertical lip changes in non-extraction cases, a multivariate approach was used to explain $75 \%$ of the variability of the changes in the extraction cases [18]. This indicates that it may be more difficult to predict the vertical lip changes in non-extraction than extraction cases, perhaps due to variability in lip compression during treatment.

The multiple regressions in the present study predicted the horizontal lip changes moderately well, explaining $41-69 \%$ of the variation in the changes that occurred. Based on a smaller sample, Shirvani and coworkers reported substantially higher multiple correlations for non-extraction cases than the present study, perhaps due to their focus on adults [34]. Once again, changes in the positions of prosthion and infradentale were most closely associated with the horizontal changes of the overlying lips. The importance of prosthion and infradentale in determining horizontal lip changes during extraction treatment has been previously demonstrated $[20,23,25,31]$. It has also appears that the horizontal changes of the lower lip can be predicted with a higher level of accuracy in extraction than non-extraction cases [18,33].

\section{Conclusion}

Non-extraction orthodontic treatment of adults and adolescents is expected to affect the lips as follows:

A. The upper and the lower lips become thinner in adults.

B. Upper lip thickness of adolescents does not change or becomes slightly thicker; the lower lip became thinner at the vermilion border and thicker at its base.

C. Males showed more vertical, but similar horizontal, lip changes than females.

D. Treatment changes in upper and lower lip position can be predicted with fair to moderate levels of accuracy.

\section{References}

1. Edler R, Agarwal P, Wertheim D, Greenhill D (2006) The use of anthropometric proportion indices in the measurement of facial attractiveness. Eur J Orthod 28(3): 274-281.

2. Bisson M, Grobbelaar A (2004) The esthetic properties of lips: A comparison of models and nonmodels. Angle Orthod 74(2): 162-166.

3. Hall D, Taylor RW, Jacobson A, Sadowsky PL, Bartolucci A (2000) The perception of optimal profile in African Americans versus white Americans as assessed by orthodontists and the lay public. Am J Orthod Dentofacial Orthop 118(5): 514-525.

4. Peck H, Peck S (1970) A concept of facial esthetics. Angle Orthod 40(4): 284-318. 
5. Auger TA, Turley PK (1999) The female soft tissue profile as presented in fashion magazines during the 1900s: a photographic analysis. Int J Adult Orthodon Orthognath Surg 14(1): 7-18.

6. Burcal RG, Laskin DM, Sperry TP (1987) Recognition of profile change after simulated orthognathic surgery. J Oral Maxillofac Surg 45(8): 666670.

7. Bergman RT, Waschak J, Borzabadi Farahani A, Murphy NC (2014) Longitudinal study of cephalometric soft tissue profile traits between the ages of 6 and 18 years. Angle Orthod 84(1): 48-55.

8. Hodges A, Rossouw PE, Campbell PM, Boley JC, Alexander RA, et al. (2009) Prediction of lip response to four first premolar extractions in white female adolescents and adults. Angle Orthod 79(3): 413-21.

9. Mamandras AH (1988) Linear changes of the maxillary and mandibular lips. Am J Orthod Dentofacial Orthop 94(5): 405-410.

10. Bishara SE, Treder JE, Jakobsen JR (1994) Facial and dental changes in adulthood. Am J Orthod Dentofacial Orthop 106(2): 175-186.

11. Formby WA, Nanda RS, Currier GF (1994) Longitudinal changes in the adult facial profile. Am J Orthod Dentofacial Orthop 105(5): 464-476.

12. Akgül AA, Toygar TU (2002) Natural craniofacial changes in the third decade of life: A longitudinal study. Am J Orthod Dentofac Orthop 122(5): 512-522.

13. Kasai K (1998) Soft tissue adaptability to hard tissues in facial profiles. Am J Orthod Dentofacial Orthop 113(6): 674-684.

14. Rudee DA (1964) Proportional profile changes concurrent with orthodontic therapy. Am J Orthod 50(6): 421-434.

15. Bloom LA (1961) Perioral profile changes in orthodontic treatment. Am J Orthod 47(5): 371-379.

16. Hershey HG (1972) Incisor tooth retraction and subsequent profile change in postadolescent female patients. Am J Orthod 61(1): 45-54.

17. Hayashida H, Ioi H, Nakata S, Takahashi I, Counts AL (2011) Effects of retraction of anterior teeth and initial soft tissue variables on lip changes in Japanese adults. Eur J Orthod 33(4): 419-426.

18. Hodges A, Rossouw PE, Campbell PM, Boley JC, Alexander RA, et al. (2009) Prediction of lip response to four first premolar extractions in white female adolescents and adults. Angle Orthod 79(3): 413-421.

19. Tadic N, Woods MG (2007) Incisal and soft tissue effects of maxillary premolar extraction in Class II treatment. Angle Orthod 77(5): 808-816.

20. Brock RA, Taylor RW, Buschang PH, Behrents RG (2005) Ethnic differences in upper lip response to incisor retraction. Am J Orthod Dentofac Orthop 127(6): 683-691.

21. Denis KL, Speidel TM (1987) Comparison of three methods of profile change prediction in the adult orthodontic patient. Am J Orthod Dentofacial Orthop 92(5): 396-402.

22. Buschang PH, Fretty K, Campbell PM (2011) Can commonly used profile planes be used to evaluate changes in lower lip position? Angle Orthod 81(4): 557-563.

23. Brooks BW, Buschang PH, Bates JD, Adams TB, English JD (2001) Predicting upper lip response to 4-piece maxillary LeFort I osteotomy. Am J Orthod Dentofac Orthop 120(2): 124-133.

24. Erdinc AE, Nanda RS, Dandajena TC (2007) Profile changes of patients treated with and without premolar extractions. Am J Orthod Dentofac Orthop 132(3): 324-331.
25. Kuhn M, Markic G, Doulis I, Göllner P, Patcas R, et al. (2016) Effect of different incisor movements on the soft tissue profile measured in reference to a rough-surfaced palatal implant. Am J Orthod Dentofac Orthop 149(3): 349-357.

26. Hershey HG (1972) Incisor tooth retraction and subsequent profile change in postadolescent female patients. Am J Orthod 61(1): 45-54

27. Huja SS, Grubaugh EL, Rummel AM, Fields HW, Beck FM (2009) Comparison of Hand-Traced and Computer-Based Cephalometric Superimpositions. Angle Orthod 79(3): 428-435.

28. Kusnoto J, Kusnoto H (2001) The effect of anterior tooth retraction on lip position of orthodontically treated adult Indonesians. Am J Orthod Dentofac Orthop 120(3): 304-307.

29. Talass MF, Tollaae L, Baker RC (1987) Soft-tissue profile changes resulting from retraction of maxillary incisors. Am J Orthod Dentofac Orthop 91(5): 385-394.

30. Caplan MJ, Shivapuja PK (1997) The effect of premolar extractions on the soft tissue profile in female adults. Angle Orthod. 67(2): 129-136.

31. Hodges AC (2006) Prediction of upper and lower lip response in orthodontic treatment involving four first premolar extractions. ProQuest pp. 1-17.

32. Rains MD, Nanda R (1982) Soft-tissue changes associated with maxillary incisor retraction. Am J Orthod 81(6): 481-488.

33. Basciftci FA, Akin M, Ileri Z, Bayram S, Qian Y, et al. (2014) Long-term stability of dentoalveolar, skeletal, and soft tissue changes after nonextraction treatment with a self-ligating system. Korean J Orthod 44(3): 119-127.

34. Shirvani A, Sadeghian S, Abbasi S (2016) Prediction of lip response to orthodontic treatment using a multivariable regression model. Dent Res J (Isfahan) 13(1): 38-45.

35. Konstantonis D (2012) The impact of extraction vs nonextraction treatment on soft tissue changes in Class I borderline malocclusions. Angle Orthod 82(2): 209-217.

36. Prahl Andersen B, Ligthelm Bakker ASWMR, Wattel E, Nanda R (1995) Adolescent growth changes in soft tissue profile. Am J Orthod Dentofac Orthop 107(5): 476-483.

37. Mamandras AH (1988) Linear changes of the maxillary and mandibular lips. Am J Orthod Dentofac Orthop 94(5): 405-410.

38. Nanda RS, Meng H, Kapila S, Goorhuis J (1990) Growth changes in the soft tissue facial profile. Angle Orthod 60(3): 177-190.

39.Zierhut EC, Joondeph DR, Artun J, Little RM (2000) Long-term profile changes associated with successfully treated extraction and nonextraction Class II Division 1 malocclusions. Angle Orthod 70(3): 208-219.

40. Subtelny JD (1959) A longitudinal study of soft tissue facial structures and their profile characteristics, defined in relation to underlying skeletal structures. Am J Orthod 45(7): 481-507.

41. Oliver BM (1982) The influence of lip thickness and strain on upper lip response to incisor retraction. Am J Orthod 82(2): 141-149.

For possible submissions Click below: 